\title{
Biomonitoring of arsenic, cadmium and lead in two artisanal and small-scale gold mining areas in Zimbabwe
}

\author{
Stefan Rakete ${ }^{1}$ (1) $\cdot$ Given Moonga ${ }^{1,2,3} \cdot$ Anna-Maria Wahl ${ }^{1} \cdot$ Viola Mambrey $^{1} \cdot$ Dennis Shoko $^{4} \cdot$ Dingani Moyo $^{5,6}$. \\ Shamiso Muteti-Fana ${ }^{7} \cdot$ Myriam Tobollik $^{8} \cdot$ Nadine Steckling-Muschack $^{1} \cdot$ Stephan Bose-O'Reilly ${ }^{1,9,10}$
}

Received: 26 March 2021 / Accepted: 9 August 2021 / Published online: 19 August 2021

(C) The Author(s) 2021

\begin{abstract}
People living and working in artisanal and small-scale gold mining (ASGM) areas are frequently exposed to elemental mercury $(\mathrm{Hg})$, which is used for gold extraction. However, additional exposure to other toxic metals such as arsenic (As), cadmium $(\mathrm{Cd})$ and lead $(\mathrm{Pb})$ may result from mining-related activities and could be ingested via dust, water or food. In these areas, only limited biomonitoring data is available for toxic metals other than Hg. In particular, data about the exposure to $\mathrm{As}, \mathrm{Cd}$ and $\mathrm{Pb}$ is unavailable for the Zimbabwean population. Therefore, we conducted a cross-sectional study in two ASGM areas in Zimbabwe to evaluate the internal exposure to these metals. In total, urine and blood samples from 207 people that identified themselves as miners were collected and analysed for $\mathrm{As}$ and $\mathrm{Cd}$ in urine as well as $\mathrm{Pb}$ in blood by GF-AAS. Median levels (interquartile ranges in $\mu \mathrm{g} / \mathrm{l}$ ) of As and $\mathrm{Pb}$ were $9.7 \mu \mathrm{g} / 1(4.0,18.5)$ and $19.7 \mu \mathrm{g} / 1(12.5,34.5)$, respectively. The 25th percentile and the median for $\mathrm{Cd}$ were below the limit of detection $(0.5 \mu \mathrm{g} / \mathrm{l})$; the 75 th percentile was at $0.9 \mu \mathrm{g} / \mathrm{l}$. The results were compared to reference values found for the general population in the USA and Germany, and a significant number of participants exceeded these values (As, $33 \% ; \mathrm{Cd}, 27 \% ; \mathrm{Pb}, 32 \%$ ), indicating a relevant exposure to toxic metals. Although not representative for the Zimbabwean population, our results demonstrate that the exposure to toxic metals is relevant for the public health in Zimbabwe and requires further investigation.
\end{abstract}

Keywords Biomonitoring $\cdot$ Toxic metals $\cdot$ Arsenic $\cdot$ Cadmium $\cdot$ Lead $\cdot$ Artisanal and small-scale gold mining $\cdot$ Zimbabwe

Responsible Editor: Lotfi Aleya

Stefan Rakete

stefan.rakete@med.uni-muenchen.de

1 Institute and Clinic for Occupational-, Social- and Environmental Medicine, University Hospital, LMU Munich, Ziemssenstr. 1, D-80336 Munich, Germany

2 Center for International Health, LMU University Hospital Munich, Munich, Germany

3 Department of Epidemiology and Biostatistics, University of Zambia, Lusaka, Zambia

4 Tailjet Consultancy Services, Harare, Zimbabwe

5 School of Public Health, Faculty of Health Sciences, Occupational Health Division, University of the Witwatersrand, Johannesburg, Republic of South Africa
6 Faculty of Medicine \& Faculty of Social Sciences, Midlands State University, Gweru, Zimbabwe

Department of Community Medicine, UZ College of Health Sciences, Harare, Zimbabwe

8 Section Environmental Medicine and Health Effects Assessment German Environment Agency, Berlin, Germany

9 Institute of Public Health, Medical Decision Making and Health Technology Assessment, Department of Public Health, Health Services Research and Health Technology Assessment, UMIT (Private University for Health Sciences, Medical Informatics and Technology), Hall in Tirol, Austria

10 University Children's Hospital Regensburg (KUNO-Clinics), Clinic St. Hedwig, University of Regensburg, Regensburg, Germany 


\section{Introduction}

Artisanal and small-scale gold mining (ASGM) is predominantly an informal, poverty-driven, poorly resourced, comparatively inefficient and transient sector. Nonetheless, it provides an income to people in many developing countries rich in gold resources, and it is estimated that about 15 million miners are involved globally (Seccatore et al. 2014). ASGM in Zimbabwe has been growing very rapidly over the last 40 years. This growth was even faster over the last 2 decades, from an estimated 300,000 miners in 2000 to over 1.5 million today (Mkodzongi and Spiegel 2020, Mudzwiti et al. 2015). This has been due to a variety of factors including a persistently shrinking economy across multiple industries along with recurrent droughts during the last 2 to 3 decades. Consequently, there has been a growth in terms of tonnages mined and processed as well as gold produced. However, this resulted in the expansion of mining sites, increased used of process chemicals such as mercury and the exposure of new rock surfaces. This has led to the worsening of adverse environmental and public health impacts due to the release of toxic metals, mainly due the use of mercury $(\mathrm{Hg})$ in the mining process (Billaud et al. 2004; Mudzwiti et al. 2015).

More than $90 \%$ of gold deposits in Zimbabwe are associated with the largely mafic/basic and cratonic greenstone belts, while the rest is located within the Limpopo Mobile Belt to the south and the Lomagundi meta-sediments in the north. The genesis of most gold deposits in Zimbabwe (>75\%) involved the generation of superheated $\left(>2000{ }^{\circ} \mathrm{C}\right)$ aqueous hydrothermal sulphide complexes at depth, in the upper mantle to lower crust. Gold is mainly transported in solution as aqueous complexes of hydrogen sulphides/bi-sulphides and chlorides as well as metal complexes (Foster 1985). Various elements, and especially heavy metal elements, have an affinity for dissolved hydrogen sulphides and chlorides in hydrothermal ore-forming solutions. This includes, but is not limited to, As, silver (Ag), Cd, $\mathrm{Hg}, \mathrm{Pb}$, selenium (Se), antimony $(\mathrm{Sb})$, tellurium $(\mathrm{Te})$, thallium $(\mathrm{Tl})$ and zinc $(\mathrm{Zn})$. These metals and many others are commonly associated with gold ores and are routinely used as pathfinders in gold exploration geochemistry (Saunders et al. 2014). Especially $\mathrm{As}, \mathrm{Cd}$ and $\mathrm{Pb}$ are relatively toxic compared to other metals and were categorized within the top ten chemicals of public health concern by the World Health Organization (International Programme on Chemical Safety (IPCS) 2010). Mining activities such as excavation, crushing and milling, which are used in ASGM, may result in the increased liberation of these toxic metals. While the precious gold is collected at the end of the mining process, the other metals may end up in the tailings dumps at mining locations and thus represent an exposure hazard for people living and working in these mining areas.

Although, biomonitoring of As (Adu-Poku et al. 2019; Basu et al. 2011; Nyanza et al. 2019; Obiri et al. 2016), Cd
(Basu et al. 2011; Obiri et al. 2016) and Pb (Gottesfeld et al. 2019; Nyanza et al. 2019; Obiri et al. 2016) has been conducted in several ASGM areas, exposure data is still relatively limited, particularly in Zimbabwe. Therefore, the purpose of this study was the analysis of $\mathrm{As}$ and $\mathrm{Cd}$ in urine as well as $\mathrm{Pb}$ in blood samples collected during a cross-sectional study involving people that identified themselves as miners in two ASGM areas in Zimbabwe. Data on $\mathrm{Hg}$ levels and health-related quality of life from this study were published elsewhere (Butscher et al. 2020; Mambrey et al. 2020; Wahl et al. 2021).

\section{Materials and methods}

\section{Study design}

This cross-sectional study was conducted within 2 weeks in March 2019 at two hospitals in the gold mining towns of Kadoma and Shurugwi Districts (Zimbabwe), respectively. Inclusion criteria for participation were a minimum age of 18 years. All females and males that identified themselves as miners and worked for at least a month were included. There were no specific exclusion criteria other than age. Participants were recruited using snowball sampling where participants recruit further participants among their colleagues. This sampling technique was used due to a widespread and hard-toreach target population. Each participant signed an informed consent form and material transfer agreement, prior to the data and sample collection. All documents were available in the three main languages English, Shona and Ndebele spoken in Zimbabwe. Altogether, 207 participants consented to participate (131 from Kadoma and 76 from Shurugwi). Participation in the study was voluntary. Participants were asked to fill out questionnaires concerning general information on demographics. To ensure a confidential analysis, the samples and data were pseudonymized. More information about the study was previously published (Mambrey et al. 2020).

\section{Urine and blood collection}

All sample containers were labelled with the participant's code for future allocation. Spot urine samples were collected using disposable urine collection cups. For transport and analysis, aliquots of the urine samples were transferred into a Urine Monovette (Sarstedt $($ )). To prevent bacterial growth and degradation, the samples were acidified with nitric acid to a $\mathrm{pH}$ of approximately 2 , which was tested with a $\mathrm{pH}$ strip. Trained health professionals took venous blood samples into $7 \mathrm{ml}$ lithium-heparin-coated tubes for trace metal analyses (Sarstedt $\left.{ }^{\circledR}\right)$ from all participants. All samples were continuously stored at $4{ }^{\circ} \mathrm{C}$. Once located in the laboratory, samples were stored at $-18^{\circ} \mathrm{C}$ until analysis. 


\section{Analysis of trace metals in urine and blood}

All samples were at least analysed in duplicate after thawing on a roll mixer. For quality control (QC), certified reference materials (ClinChek®, Recipe, Munich, Germany) for whole blood and urine were analysed daily, and the sample analysis was only continued if the QC results were within the given specifications. As, $\mathrm{Cd}$ and $\mathrm{Pb}$ were analysed by graphite furnace atomic absorption spectroscopy (GF AAS, AAnalyst 600, Perkin Elmer, Rodgau, Germany) with the furnace programmes according to the recommendations of the manufacturer. The individual specifications for each element can be found below. The quantitation of all elements based on the standard addition method and the limit of detection (LOD) was calculated from the blank signal.

Analysis of total As in urine Total As in urine was analysed at a detection wavelength of $193.7 \mathrm{~nm}$. Urine samples were diluted sixfold with $0.01 \%$ Triton-X in $0.13 \%$ nitric acid. Twenty microlitres of this dilution were automatically pipetted into the graphite tube of the GF-AAS. Five micrograms of $\mathrm{Pd}$ (as $\mathrm{Pd}$ $\left.\left(\mathrm{NO}_{3}\right)_{2}\right)$ and $3 \mu \mathrm{g} \mathrm{Mg}\left(\mathrm{NO}_{3}\right)_{2}$ were added as matrix modifiers. For standard addition, 10 and $20 \mathrm{pg}$ As were directly added to the sample in the graphite tube, respectively. The LOD was at $0.5 \mu \mathrm{g} / \mathrm{l}$.

Analysis of $\mathrm{Cd}$ in urine $\mathrm{Cd}$ in urine was analysed at a detection wavelength of $228.8 \mathrm{~nm}$. Urine samples were diluted fourfold with $0.01 \%$ Triton-X in $0.13 \%$ nitric acid. Twenty microlitres of this dilution were automatically pipetted into the graphite tube of the GF-AAS. Fifty micrograms of $\mathrm{NH}_{4} \mathrm{H}_{2} \mathrm{PO}_{4}$ and $3 \mu \mathrm{g} \mathrm{Mg}\left(\mathrm{NO}_{3}\right)_{2}$ were added as matrix modifiers. For standard addition, 0.5 and $1 \mathrm{pg} \mathrm{Cd}$ were directly added to the sample in the graphite tube, respectively. The LOD was at $0.5 \mu \mathrm{g} / \mathrm{l}$.

Analysis of $\mathrm{Pb}$ in blood $\mathrm{Pb}$ in blood was analysed at a detection wavelength of $193.7 \mathrm{~nm}$. Blood samples were diluted tenfold with $0.05 \%$ Triton-X. Twenty microlitres of this dilution were automatically pipetted into the graphite tube of the GF-AAS. Fifty micrograms of $\mathrm{NH}_{4} \mathrm{H}_{2} \mathrm{PO}_{4}$ and $3 \mu \mathrm{g} \mathrm{Mg}\left(\mathrm{NO}_{3}\right)_{2}$ were added as matrix modifiers. For standard addition, 5 and $10 \mathrm{pg}$ $\mathrm{Pb}$ were directly added to the sample in the graphite tube, respectively. The LOD was at $1.0 \mu \mathrm{g} / \mathrm{l}$.

\section{Analysis of creatinine in urine}

Creatinine in urine samples was determined for creatininecorrected levels of toxic metals in urine. Creatinine-corrected urine values were considered in order to account for the influence of the effect of urine dilution on the exposure indicator. Urine samples were sent to the central laboratory of University Hospital of LMU and analysed with Cobas C702 using the Jaffé method. Creatininecorrected values from urine samples with creatinine levels $<0.3 \mathrm{~g} / 1$ and $>3.0 \mathrm{~g} / \mathrm{l}$ were excluded from statistical analysis.

\section{Statistical analysis}

All data analyses were performed with SPSS (version 26, IBM). One participant was excluded from statistical analysis, as the urine sample apparently contained blood. For samples below the LOD, the result was set to $1 / 2$ LOD for further statistical analysis. Descriptive analysis included the geometric mean, minimum, maximum, median, 25 th percentile, 75 th percentile and 95th percentile. Differences in toxic metal concentrations between groups (gender, living area and self-reported fish consumption) were tested using the Mann-Whitney $U$ test. Continuous variables (toxic metals, age, area years and mining years) were correlated using the Spearman correlation. Results for $\mathrm{Hg}$ in blood in urine and blood from the same participants used for correlation analyses were previously published elsewhere (Mambrey et al. 2020).

\section{Results}

Demographic information on the study population can be found in Table 1. One sample had to be excluded due to obvious sample contamination. Consequently, the levels of As and $\mathrm{Cd}$ in urine as well as the levels of $\mathrm{Pb}$ in blood were analysed for 206 participants, and the results are given in Table 2. Although urine samples with creatinine levels $<0.3$ or $>3.0 \mathrm{~g} / \mathrm{l}$ should preferably not be used for biomonitoring, we decided to only refrain from creatinine correction, as sampling could not be repeated (Cocker et al. 2011). Therefore, thirteen urine samples with urinary creatinine levels outside of this range were excluded from creatinine correction. The participants' levels of $\mathrm{As}$ in urine and $\mathrm{Pb}$ in blood follow a log-normal distribution (Figure S1), which was expected for this population. For $\mathrm{Cd}$ in urine, a log-normal distribution is anticipated, too. However, the majority of samples were below the LOD. The results were further stratified by gender ( 82 $\%$ male), living area (63\% Kadoma) and self-reported fish consumption (80\% at least once a week), and differences were tested for significance (Table S1). For gender, urinary

Table 1 Demographic information on the study population

\begin{tabular}{llll}
\hline Age & $N$ & 207 & \\
& Median (min.-max.) & $38(18-77)$ & \\
\hline \multirow{3}{*}{ Gender } & & $\boldsymbol{N}$ & $\mathbf{( \% )}$ \\
& Males & 169 & $(81.6)$ \\
Living area & Females & 38 & $(18.4)$ \\
& Kadoma & 131 & $(63.3)$ \\
Fish consumption & Shurugwi & 76 & $(36.7)$ \\
& < once a week & 42 & $(20.3)$ \\
& $>$ once a week & 165 & $(79.7)$ \\
\hline
\end{tabular}


Table 2 Descriptive analysis of biomonitoring results for urinary levels of $\mathrm{As}$ and $\mathrm{Cd}$ and blood levels of $\mathrm{Pb}$. Creatinine correction was not applied for urine samples with creatinine levels below 0.3 or above 3.0 $\mathrm{g} / \mathrm{l}$. Results were compared to international reference and threshold values for $\mathrm{As}$ and $\mathrm{Cd}$ in urine and $\mathrm{Pb}$ in blood, and the percentage of exceedances in this study is given in the brackets. Reference values represent the actual internal exposure of a representative population.
Threshold values were derived from toxicological data. NHANES National Health and Nutrition Examination Survey, USA, UBA German Environment Agency, $C D C$ Centers for Disease Control and Prevention, USA, NIOSH National Institute for Occupational Safety and Health, USA, HBM-II human biological monitoring alert level (Centers of Disease Preventions and Control (CDC) 2019, Schulz et al. 2011, UBA - German Environment Agency 2019)

\begin{tabular}{|c|c|c|c|c|c|c|}
\hline & \multirow{2}{*}{$\begin{array}{l}\text { Creatinine in urine } \\
\mathrm{g} / \mathrm{l}\end{array}$} & \multicolumn{2}{|c|}{ As in urine } & \multicolumn{2}{|c|}{$\mathrm{Cd}$ in urine } & \multirow{2}{*}{$\begin{array}{l}\mathrm{Pb} \text { in blood } \\
\mu \mathrm{g} / 1\end{array}$} \\
\hline & & $\mu \mathrm{g} / 1$ & $\mu \mathrm{g} / \mathrm{g}$ crea. & $\mu \mathrm{g} / 1$ & $\mu \mathrm{g} / \mathrm{g}$ crea. & \\
\hline $\mathrm{N}$ & 206 & 206 & 193 & 206 & 193 & 206 \\
\hline LOD & 0.1 & 0.5 & & 0.5 & & 1 \\
\hline$<$ LOD & 0 & 12 & & 120 & & 0 \\
\hline GM & 1,3 & 7.2 & 5.6 & 0.6 & 0.4 & 21.9 \\
\hline Minimum & 0.1 & $<$ LOI & & $<$ LOD & & 6.6 \\
\hline 25 th percentile & 1.0 & 3.7 & 2.7 & $<$ LOD & & 12.5 \\
\hline Median & 1.4 & 9.7 & 6.5 & $<\mathrm{LOD}$ & & 19.7 \\
\hline 75th percentile & 2.0 & 17.1 & 13.2 & 0.9 & 0.7 & 34.1 \\
\hline 95th percentile & 2.8 & 47.1 & 33.6 & 3.6 & 1.8 & 76.4 \\
\hline \multirow[t]{2}{*}{ Maximum } & 4.6 & 460.5 & 250.3 & 11.4 & 4.9 & 275.7 \\
\hline & & \multicolumn{2}{|c|}{ As in urine $[\mu \mathrm{g} / 1]$} & \multicolumn{2}{|c|}{$\mathrm{Cd}$ in urine $[\mu \mathrm{g} / \mathrm{l}]$} & $\mathrm{Pb}$ in blood $[\mu \mathrm{g} / \mathrm{l}]$ \\
\hline \multicolumn{7}{|c|}{ Reference values (exceedances in \%) } \\
\hline \multicolumn{2}{|c|}{ NHANES } & \multicolumn{2}{|c|}{$49.9(3.6)$} & \multicolumn{2}{|l|}{$1.1(22)$} & $28.9(32)$ \\
\hline \multicolumn{2}{|l|}{ UBA } & \multicolumn{2}{|c|}{$15.0(33)$} & \multicolumn{2}{|c|}{$0.8(27)$} & $\begin{array}{l}30(\%, 24 \%) \\
40(\hat{\jmath}, 20 \%)\end{array}$ \\
\hline \multicolumn{7}{|c|}{ Threshold values (exceedances in \%) } \\
\hline \multicolumn{2}{|c|}{ NIOSH (CDC) } & \multicolumn{2}{|l|}{ n.a. } & \multicolumn{2}{|l|}{ n.a } & $50(11)$ \\
\hline \multicolumn{2}{|l|}{ UBA (HBM-II) } & \multicolumn{2}{|l|}{ n.a. } & \multicolumn{2}{|l|}{$4.0(4)$} & n.a. \\
\hline
\end{tabular}

$L O D$ limit of detection, $<L O D$ number of results below limit of detection, GM geometric mean, n.a. not available

As levels were significantly higher in women. In contrast, blood $\mathrm{Pb}$ levels were significantly higher in men. For the area of living, significantly higher levels of As in urine were found for Kadoma if corrected for urinary creatinine. For self-reported fish consumption, no significant differences were found for any toxic metal.

For further evaluation, the results were compared to available international reference and threshold values from Germany and the USA (Centers of Disease Preventions and Control (CDC) 2019, Schulz et al. 2011, UBA - German Environment Agency 2019). The reference and threshold values for $\mathrm{As}, \mathrm{Cd}$ and $\mathrm{Pb}$ as well as the percentage of participants that exceeded these values are given in Table 2. The 95th percentiles of $\mathrm{Cd}$ and $\mathrm{Pb}$ found in this study were higher than the reference values of the NHANES and UBA data. For As in urine, the 95th percentile found in this study was higher than the value proposed by UBA but comparable to NHANES.

The results for the correlation between toxic metals (including $\mathrm{Hg}$ ), age, area years and mining years are given in Table S2. In general, correlation of the biomonitoring results with age, area years and mining years was found to be very low. However, $\mathrm{Hg}$ levels in urine and blood showed a weak positive correlation with mining years. In contrast, $\mathrm{Cd}$ in urine showed a weak negative correlation with age. If the levels of toxic metals were correlated to each other, a strong positive relationship was found for non-corrected and corrected levels of $\mathrm{As}, \mathrm{Cd}$ and $\mathrm{Hg}$ in urine, respectively. Furthermore, a strong correlation was found for $\mathrm{Hg}$ in urine and $\mathrm{Hg}$ in blood. Whereas $\mathrm{As}, \mathrm{Cd}$ and $\mathrm{Pb}$ mainly showed no to very weak correlation among each other, $\mathrm{Hg}$ levels in urine and blood showed a relatively moderate positive correlation with $\mathrm{As}, \mathrm{Cd}$ and $\mathrm{Pb}$.

\section{Discussion}

As explained in the introduction, toxic metals may be associated with gold-containing ores in ASGM areas. Therefore, it seems plausible that elevated $\mathrm{As}, \mathrm{Cd}$ and $\mathrm{Pb}$ levels in the participants are related to the mining activities in Kadoma and Shurugwi. Below, we discuss the results for the individual metals and compare them to previously published studies in 
Table 3 Comparison of the study results (all values are given in $\mu \mathrm{g} / \mathrm{l}$ ) with other studies in mining areas. All values are given as 25th percentile (P25), median and 75 th percentile (P75) unless marked otherwise $(\#)$

\begin{tabular}{|c|c|c|c|}
\hline Parameter $[\mu \mathrm{g} / 1]$ & Values measured in this Study & $\begin{array}{l}\text { Values measured in studies in } \\
\text { current and former mining areas (country) }\end{array}$ & Reference \\
\hline & P25-median-P75 & P25-median-P75 & \\
\hline \multirow[t]{5}{*}{ As in urine } & $4.0-10.0-18.5$ & 4.9-9.4-15.1 (Tanzania) $)^{1}$ & Nyanza et al. (2019) \\
\hline & & 73.2-100.2-135.3 (Ghana) & Basu et al. (2011) \\
\hline & & $11.1-16.5-19.4$ (Mexico) $^{2}$ & Moreno et al. (2010) \\
\hline & & $0.5-1.17-1.93(\text { Spain })^{2}$ & Molina-Villalba et al. (2015) \\
\hline & & 0.06 (Guatemala) & Basu et al. (2010) \\
\hline \multirow[t]{3}{*}{$\mathrm{Cd}$ in urine } & $<$ LOD $<$ LOD -0.9 & $0.25-0.36-0.6$ (Ghana) & Basu et al. (2011) \\
\hline & & $0.13-0.29-0.46{\text { (Spain })^{2}}^{2}$ & Molina-Villalba et al. (2015) \\
\hline & & 0.11 (Guatemala) & Basu et al. (2010) \\
\hline \multirow[t]{6}{*}{$\mathrm{Pb}$ in blood } & $12.5-19.9-34.5$ & 16.9-25.4-33.7 (Tanzania) $)^{1}$ & Nyanza et al. (2019) \\
\hline & & 64-94-113 (Mexico $)^{2}$ & Moreno et al. (2010) \\
\hline & & 26.7 (Guatemala) & Basu et al. (2010) \\
\hline & & 13.0 (Zambia) & Yabe et al. (2020) \\
\hline & & 21.5 (Nigeria) & Gottesfeld et al. (2019) \\
\hline & & 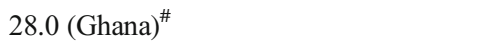 & Obiri et al. (2016) \\
\hline
\end{tabular}

\footnotetext{
${ }^{1}$ Pregnant women

${ }^{2}$ Children

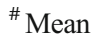

$L O D$ limit of detection
}

mining areas (Table 3). Although some of the studies found comparable results, the exposure to toxic metals likely depends on multiple factors such as the study population, the local concentrations of metals in the ore, the diet and many others. Generally, living close to mining areas seems to have a significant effect on the body burden (Basu et al. 2010, Molina-Villalba et al. 2015, Nemery and Banza Lubaba Nkulu 2018, Obiri et al. 2016). One possible explanation is that contaminated mining tailings contribute to the exposure to toxic metals by causing elevated concentrations in water, food and airborne dust (Moreno et al. 2010; van Straaten 2000).

Arsenic In contrast to the other metals, the reference values for As in urine from Germany (UBA) and the USA (NHANES) differ considerably from one another $(15.0 \mathrm{vs} 49.9 \mu \mathrm{g} / \mathrm{l})$. This is likely due to different exposures to As, e.g. by fish consumption and other sources such as drinking water. However, reference values represent the actual exposure in the general population and cannot be used for toxicological evaluation. Consequently, the number of participants in this study that were above reference values for As heavily depends on which value will be used. It seems that the exposure to As is more comparable to the US population. However, we did not analyse the As species for differentiate inorganic $(\mathrm{As}(\mathrm{IIII}), \mathrm{As}(\mathrm{V}))$ and organic (e.g. arsenobetaine) As species. A major source of organic As is fish. However, self-reported fish consumption had no effect on
As levels in urine. Zimbabwe has no access to open sea. Consequently, the consumed fish is commonly freshwater fish which usually contains relatively low amounts of As. The elevated levels of As in women and participants from Kadoma may be explained by different dietary patterns or a generally elevated exposure to As due to mining activities. Our results were comparable to what has been found in an ASGM area in Tanzania, but also in non-active mining areas in Mexico (Moreno et al. 2010; Nyanza et al. 2019). However, Basu et al. found a tenfold higher median As level in a Ghanaian ASGM study (Basu et al. 2011). In contrast, studies from Spain and Guatemala found relatively low levels of As in the urine (Basu et al. 2010; Molina-Villalba et al. 2015).

Cadmium Most of the samples were below the LOD, indicating a generally low exposure. Still, a considerable number of participants were above the references and threshold values. $\mathrm{Cd}$ levels are generally elevated in smokers. Unfortunately, we do not have the data for smoking in our study. In Zimbabwe's mining areas, far more men smoke compared to women (Billaud et al. 2004). However, this was not reflected in our results, where women were more frequently above international reference and threshold values for $\mathrm{Cd}$ (data not shown). For Cd in urine, the studies from Ghana, Guatemala and Spain showed very similar results (Basu et al. 2010; Basu et al. 2011; Molina-Villalba et al. 2015). Therefore, Cd 
exposure in ASGM and other mining areas seems to be relatively low compared to other toxic metals.

Lead About a third of the participants were above international reference values. The exposure to lead could be via contaminated drinking water, although the uptake of $\mathrm{Pb}$ in the gastrointestinal tract of adults is considered relatively low and airborne dust due to mining activities. Besides this, $\mathrm{Pb}$ exposure could be due to emissions of leaded gasoline, which was used longer in Africa than in the US or Europe (Todd and Hazel 2010). Therefore, the recent exposure to these emissions might still be reflected by elevated blood $\mathrm{Pb}$ levels. The results of this study are comparable to what has been found in other studies (Basu et al. 2010; Gottesfeld et al. 2019; Obiri et al. 2016; Yabe et al. 2020). However, in a study from Mexico, blood $\mathrm{Pb}$ levels were significantly higher (Moreno et al. 2010).

\section{Limitations}

Unfortunately, we did not have access to information about smoking, diet other than fish and levels of toxic metals in water, food, soil and air, thus limiting a more thorough exposure assessment. Additionally, we were not able to speciate As due to technical and financial limitations, further limiting exposure assessment and comparison with other studies. For As and $\mathrm{Cd}$, the sensitivity of the analytical method was too low for some samples. In fact, $\mathrm{Cd}$ could not be detected in more than half of the samples, clearly limiting $\mathrm{Cd}$ exposure assessment. Nevertheless, the LOD was below the used reference and threshold levels. However, a relatively high number of participants were above international reference values (22\% $>$ NHANES, $27 \%$ > UBA). This may be explained by the fact that the $\mathrm{Cd}$ levels of 51 samples were relatively close to the LOD. Consequently, these results may be subject to some uncertainty regarding absolute quantitation. Furthermore, the inclusion of a control group from a non-mining area in Zimbabwe may have provided information if the exposure to $\mathrm{As}, \mathrm{Cd}$ and $\mathrm{Pb}$ is actually caused by mining activities. However, this study was designed as a cross-sectional study as many studies had demonstrated that mining activities are associated with increased exposure to toxic metals.

\section{Conclusions}

This is, to the best of our knowledge, the first study that analysed the urinary levels of As and $\mathrm{Cd}$ as well as the blood levels of $\mathrm{Pb}$ in people identifying themselves as artisanal and small-scale gold miners in Zimbabwe. A high proportion of the participants had $\mathrm{As}, \mathrm{Cd}$ and $\mathrm{Pb}$ levels above international reference levels. Therefore, the exposure to toxic metals in the two ASGM areas in Zimbabwe is relevant to public health and should be the subject of further investigation to clarify the influence of possible confounders, e.g. the diet. Furthermore, the exposure to toxic metals should be assessed in the general population of Zimbabwe to investigate if the results found in this study are related to ASGM activities.

Supplementary Information The online version contains supplementary material available at https://doi.org/10.1007/s11356-021-15940-w.

Acknowledgements The authors would like to thank the funding institution and our team in Zimbabwe and Germany. Especially we would like to thank Stefan Gröbmair, Evans Rudzvidzo, Dr. Godknows Madziva, Brian Chizaza, Josephine Mashamba, Jana Becker, James Rooney, and Friederike Butscher.

Author contribution Conceptualization, SR, VM, DS, DN, SM, NS and $\mathrm{SB}$; data curation, GM, VM and SB; formal analysis, SR, GM and VM; funding acquisition, VM, DS, DM, NS and SB; investigation, SR, VM, DS, DM, SM, MT and SB; methodology, SR, GM, VM, DM, SM, NS and SB; project administration, VM, DS, DM, NS and SB; supervision, $\mathrm{SR}, \mathrm{NS}$ and $\mathrm{SB}$; validation, $\mathrm{SR}$; visualization, $\mathrm{GM}, \mathrm{AW}$ and $\mathrm{SB}$; writing (original draft), SR, GM, AW, VM, DS, DM, SM, MT, and SB; writing (review and editing), SR, GM, AW, VM, DS, DM, SM, MT, NS and SB.

Funding Open Access funding enabled and organized by Projekt DEAL. This research was funded by the German Federal Ministry for the Environment, Nature Conservation and Nuclear Safety (BMU IG II 2 45083 - 4/0, SB); SB and NS received funding from the European Union's Seventh Programme under grant agreement No 603946 (Health and Environment-Wide Associations Based on Large Population Surveys, HEALS).

Data availability The datasets used and/or analysed during the current study may be made available from the corresponding author on reasonable request.

\section{Declarations}

Ethics approval and consent to participate Approval for conducting the study was gained from the Ministry of Health in Zimbabwe and the respective local and regional authorities. The Ethics Committee of the Medical Research Council and the Zimbabwe Research Council (MRCZ/A/2367, September 26, 2018, and February 25, 2019) and the Ludwig Maximilian University of Munich (18-421, October 15, 2018) approved the study protocols and gave their permissions. In agreement with the Helsinki Declaration of Ethics Code for experiments with human subjects, the study was performed. Each participant signed an informed consent form and material transfer agreement, prior to the data and sample collection. All documents were available in the three main languages: English, Shona and Ndebele spoken in Zimbabwe.

Consent for publication The participants signed informed consent regarding publishing their data.

Competing interests The authors declare no competing interests.

Open Access This article is licensed under a Creative Commons Attribution 4.0 International License, which permits use, sharing, adaptation, distribution and reproduction in any medium or format, as long as you give appropriate credit to the original author(s) and the source, 
provide a link to the Creative Commons licence, and indicate if changes were made. The images or other third party material in this article are included in the article's Creative Commons licence, unless indicated otherwise in a credit line to the material. If material is not included in the article's Creative Commons licence and your intended use is not permitted by statutory regulation or exceeds the permitted use, you will need to obtain permission directly from the copyright holder. To view a copy of this licence, visit http://creativecommons.org/licenses/by/4.0/.

\section{References}

Adu-Poku B, Asiedu N, Akoto O, Ataki J (2019) Modelling the distribution of arsenic and mercury in urine using chemometric tools. Cogent Chem 5:1586064. https://doi.org/10.1080/23312009.2019.1586064

Basu N, Abare M, Buchanan S, Cryderman D, Nam D-H, Sirkin S, Schmitt S, Hu H (2010) A combined ecological and epidemiologic investigation of metal exposures amongst Indigenous peoples near the Marlin Mine in Western Guatemala. Sci Total Environ 409:70 77. https://doi.org/10.1016/j.scitotenv.2010.09.041

Basu N, Nam D-H, Kwansaa-Ansah E, Renne EP, Nriagu JO (2011) Multiple metals exposure in a small-scale artisanal gold mining community. Environ Res 111:463-467. https://doi.org/10.1016/j. envres.2011.02.006

Billaud P, Laperche V, Maury-Brachet R, Boudou A, Shoko D, Kahwai S, Freyssinet P (2004) Removal of barriers to the introduction of cleaner artisanal gold mining and extraction technologies in Kadoma, Zimbabwe - Final report, part A Environmental assessment. UNIDO Project EG/GLO/01/G34 No.03/089. BRGM Project Nr 53320-FR BRGM (Bureau de Recherches Géologiques et Minières), www. unites.uqam.ca/gmf/intranet/gmp, Orleans, France

Butscher F-M, Rakete S, Tobollik M, Mambrey V, Moyo D, Shoko D, Muteti-Fana S, Steckling-Muschack N, Bose-O'Reilly S (2020) Health-related quality of life (EQ-5D + C) among people living in artisanal and small-scale gold mining areas in Zimbabwe: a crosssectional study. Health Qual Life Outcomes 18:284. https://doi.org/ 10.1186/s12955-020-01530-w

Centers of Disease Preventions and Control (CDC) 2019: Fourth National Report on Human Exposure to Environmental Chemicals - Updated Tables

Cocker J, Mason HJ, Warren ND, Cotton RJ (2011) Creatinine adjustment of biological monitoring results. Occup Med 61:349-353. https://doi.org/10.1093/occmed/kqr084

Foster RP (1985) Major controls of Archaean gold mineralization in Zimbabwe. Trans Geol Soc S Afr 88:109-133

Gottesfeld P, Meltzer G, Costello S, Greig J, Thurtle N, Bil K, Mwangombe BJ, Nota MM (2019) Declining blood lead levels among small-scale miners participating in a safer mining pilot programme in Nigeria. Occup Environ Med 76:849-853. https://doi. org/10.1136/oemed-2019-105830

International Programme on Chemical Safety (IPCS), (2010): Ten chemicals of major public health concern. https://www.who.int/ipcs/assessment/ public_health/chemicals_phc/en/ Accessed July, 5th 2021

Mambrey $\bar{V}$, Rakete S, Tobollik M, Shoko D, Moyo D, Schutzmeier P, Steckling-Muschack N, Muteti-Fana S, Bose-O'Reilly S (2020) Artisanal and small-scale gold mining: a cross-sectional assessment of occupational mercury exposure and exposure risk factors in Kadoma and Shurugwi, Zimbabwe. Environ Res 184:109379

Mkodzongi G, Spiegel SJ (2020) Mobility, temporary migration and changing livelihoods in Zimbabwe's artisanal mining sector. Extr Ind Soc 7:994-1001. https://doi.org/10.1016/j.exis.2020.05.001

Molina-Villalba I, Lacasaña M, Rodríguez-Barranco M, Hernández AF, Gonzalez-Alzaga B, Aguilar-Garduño C, Gil F (2015) Biomonitoring of arsenic, cadmium, lead, manganese and mercury in urine and hair of children living near mining and industrial areas. Chemosphere 124:8391. https://doi.org/10.1016/j.chemosphere.2014.11.016

Moreno ME, Acosta-Saavedra LC, Meza-Figueroa D, Vera E, Cebrian ME, Ostrosky-Wegman P, Calderon-Aranda ES (2010) Biomonitoring of metal in children living in a mine tailings zone in Southern Mexico: a pilot study. Int J Hyg Environ Health 213: 252-258. https://doi.org/10.1016/j.ijheh.2010.03.005

Mudzwiti P, Mukwakwami N, Mungoni M, I M (2015) A golden opportunity: scoping study of artisanal and small scale mining in Zimbabwe. Harare, Zimbabwe

Nemery B, Banza Lubaba Nkulu C (2018) Assessing exposure to metals using biomonitoring: achievements and challenges experienced through surveys in low- and middle-income countries. Toxicol Lett 298:13-18. https://doi.org/10.1016/j.toxlet.2018.06.004

Nyanza EC, Bernier FP, Manyama M, Hatfield J, Martin JW, Dewey D (2019) Maternal exposure to arsenic and mercury in small-scale gold mining areas of Northern Tanzania. Environ Res 173:432-442. https://doi.org/10.1016/j.envint.2019.105450

Obiri S, Yeboah PO, Osae S, Adu-Kumi S (2016) Levels of arsenic, mercury, cadmium, copper, lead, zinc and manganese in serum and whole blood of resident adults from mining and non-mining communities in Ghana. Environ Sci Pollut Res 23:16589-16597. https://doi.org/10.1007/s11356-016-6537-0

Saunders J, Hofstra A, Goldfarb R, Reed MH (2014) Geochemistry of hydrothermal gold deposits. In Heinrich D. Holland, Karl K (Eds.) Treatise on Geochemistry: Second Edition 13, 383-424. https://doi. org/10.1016/B978-0-08-095975-7.01117-7

Schulz C, Wilhelm M, Heudorf U, Kolossa-Gehring M (2011) Update of the reference and HBM values derived by the German Human Biomonitoring Commission. Int J Hyg Environ Health 215:26-35. https://doi.org/10.1016/j.ijheh.2011.06.007

Seccatore J, Veiga M, Origliasso C, Marin T, De Tomi G (2014) An estimation of the artisanal small-scale production of gold in the world. Sci Total Environ 496:662-667. https://doi.org/10.1016/j. scitotenv.2014.05.003

Todd DT, Hazel (2010) Outcome and Influence Evaluation of the UNEP Partnership for Clean Fuels and Vehicles (PCFV) United Nations Environment Programme (UNEP). https://wedocs.unep.org/ bitstream/handle/20.500.11822/274/Outcome_and_Influence_ Evaluation_of_the_UNEP_Based_Partnership_for_Clean_Fuels_ and_Vehicles_(PCFV).pdf? sequence=1\&isAllowed=y

UBA - German Environment Agency (2019) Reference values (RV95) for antimony, arsenic and metals $(\mathrm{Pb}, \mathrm{Cd}, \mathrm{Ni}, \mathrm{Hg}, \mathrm{Pt}, \mathrm{Tl}, \mathrm{U})$ in urine or in the blood. https://www.umweltbundesamt.de/sites/default/ files/medien_/4031/dokumente/tab._referenzwerte_-_metalle_30. _september_2019_aktualisiert.pdf, Accessed: July, 5th 2020

van Straaten P (2000) Mercury contamination associated with small-scale gold mining in Tanzania and Zimbabwe. Sci Total Environ 259: 105-113. https://doi.org/10.1016/S0048-9697(00)00553-2

Wahl A-M, Bose-O'Reilly S, Mambrey V, Rooney JPK, Shoko D, Moyo D, Muteti-Fana S, Steckling-Muschack N, Rakete S (2021) Analysis of the mercury distribution in blood as a potential tool for exposure assessment - results from two artisanal and small-scale gold mining areas in Zimbabwe. Biol Trace Elem Res. https://doi.org/10.1007/ s12011-021-02714-1

Yabe J, Nakayama SMM, Nakata H, Toyomaki H, Yohannes YB, Muzandu K, Kataba A, Zyambo G, Hiwatari M, Narita D, Yamada D, Hangoma P, Munyinda NS, Mufune T, Ikenaka Y, Choongo K, Ishizuka M (2020) Current trends of blood lead levels, distribution patterns and exposure variations among household members in Kabwe, Zambia. Chemosphere 243:125412. https:// doi.org/10.1016/j.chemosphere.2019.125412

Publisher's note Springer Nature remains neutral with regard to jurisdictional claims in published maps and institutional affiliations. 